\title{
Analisis Penyebab Kegagalan Pemberian Asi Eksklusif pada Bayi di RSUD Tgk. Chik Ditiro Kabupaten Pidie
}

\author{
Idawati $1^{*}$, Rita Mirdahni ${ }^{1}$, Susi Andriani ${ }^{1}$, Yuliana ${ }^{1}$ \\ ${ }^{1}$ STIKes Medika Nurul Islam, Indonesia \\ "Korespondensi: idawatiwati45@gmail.com
}

\begin{tabular}{|c|c|}
\hline $\operatorname{lnf}$ & \\
\hline $\begin{array}{l}\text { Diterin } \\
\text { Novemb } \\
\text { Disetu } \\
\text { Novemb } \\
\text { Dipublika } \\
\text { Novemb }\end{array}$ & $\begin{array}{l}\text { Menyusui memiliki peranan penting terhadap tumbuh kembang bayi, } \\
\text { kegagalan untuk memberikan ASI eksklusif dapat menyebabkan tingginya } \\
\text { angka kematian bayi. Penelitian ini dilakukan untuk mengetahui mengapa } \\
\text { bayi baru lahir di RSUD Tgk Chik Ditiro tidak mendapatkan ASI eksklusif } \\
\text { Kabupaten Pidie Chik Ditiro. Metode : jenis penelitian yaitu analitik } \\
\text { memakai pendekatan crossectional, objek penelitian yakni seluruh ibu } \\
\text { bersalin dan menyusui yang berjumlah } 85 \text { orang. Hasil Penelitian : Hasil } \\
\text { penelitian pada aspek pengetahuan didapat hasil } p=0,000 \text {, kategori sikap } \\
\text { diperoleh nilai sig. } 0,000, \text { variabel peran penolong didapat } p=0,000 \text {, }\end{array}$ \\
\hline $\begin{array}{r}\text { Keyw } \\
\text { Kegac } \\
\text { Pemberi } \\
\text { Eksk }\end{array}$ & $\begin{array}{l}\text { variabel tradisi diperoleh } p=0,000 \text { yang artinya variabel tersebut signifikan } \\
\text { dengan pemberian ASI eksklusif pada bayi dan variabel umur ibu } \\
\text { diperoleh nilai } p=0,131 \text {, variabel pendidikan diperoleh } p=0,526 \text {, variabel } \\
\text { pekerjaan diperoleh nilai } p=0,576 \text {, variabel pendapatan diperoleh } p= \\
0,271 \text {, variabel paritas diperoleh } p=0,477 \text {, variabel usia bayi diperoleh nilai }\end{array}$ \\
\hline $\begin{array}{l}\text { (c) } 2021 \text { The } \\
\text { Author(s): This is } \\
\text { an open-access } \\
\text { article distributed } \\
\text { under the terms of } \\
\text { the Creative }\end{array}$ & $\begin{array}{l}p=0,560 \text {, variabel prilaku dengan hasil } p=0,402 \text { yang artinya variabel } \\
\text { tersebut tidak mempunyai nilai yang bermakna terhadap pelaksanaan ASI } \\
\text { ekslusif terhadap bayi. Kesimpulan : terdapat pengaruh antara } \\
\text { pengetahuan, sikap ibu dan tradisi dalam pemberian ASI eksklusif namun } \\
\text { Variabel peran penolong persalinan merupakan variabel yang paling } \\
\text { dominan berpengaruh terhadap pemberian ASI eksklusif. }\end{array}$ \\
\hline $\begin{array}{l}\text { Commons } \\
\text { Attribution } \\
\text { ShareAlike (CC BY- } \\
\text { SA 4.0) }\end{array}$ & $\begin{array}{l}\text { Abstract } \\
\text { Breastfeeding has an important role in infant growth and development, } \\
\text { failure to provide exclusive breastfeeding can lead to high infant mortality } \\
\text { rates. This study was conducted to find out why newborns did not receive } \\
\text { exclusive breastfeeding in Pidie Chik Ditiro Regency. Methods: the type of } \\
\text { research is analytic using a cross-sectional approach, the object of the }\end{array}$ \\
\hline & $\begin{array}{l}\text { research is all } 85 \text { women giving birth and breastfeeding. Research Results: } \\
\text { The results of the research on the aspect of knowledge obtained } p= \\
0.000 \text {, the attitude category obtained a sig value. } 0.000 \text {, the role of the } \\
\text { helper variable was obtained } p=0.000 \text {, the tradition variable was obtained } \\
p=0.000 \text { which means that the variable was significant with exclusive } \\
\text { breastfeeding for infants and the mother's age variable obtained } p \text { value }= \\
0.131 \text {, the education variable obtained } p=0.526 \text {, the employment variable } \\
\text { obtained } p \text { value }=0.576 \text {, income variable obtained } p=0.271 \text {, parity } \\
\text { variable obtained } p=0.477 \text {, infant age variable obtained } p \text { value }=0.560 \text {, } \\
\text { behavioral variable with } p=0.402 \text { which means that the variable has no } \\
\text { significant value to the implementation. Conclusion: there is an influence } \\
\text { between knowledge, mother's attitude and tradition in exclusive } \\
\text { breastfeedingThe variable of the role of birth attendant is the most } \\
\text { dominant variable affecting exclusive breastfeeding. }\end{array}$ \\
\hline
\end{tabular}




\section{Pendahuluan}

Menyusui memiliki peran yang sangat bermakna dalam tumbuh kembang anak. Memberikan ASI secara terus menerus sampai usia 6 bulan kemudian diteruskan selama dua tahun ternyata dapat meningkatkan sistem kekebalan tubuh bayi baru lahir. Pemberian ASI terus menerus sampai usia dua tahun masih jarang terjadi, secara global hanya $38 \%$ ibu yang melakukannya. lbu menyusui yang tidak ideal, akan memberikan kontribusi 800.000 kematian bayi baru lahir. Pada tahun 2025, Organisasi Kesehatan Dunia (WHO) menginginkan capaian ASI pada en am bulan diawal kelahiran minimal $50 \%$. Hampir semua negara berkembang yang mempunyai ketercapaian yang rendah terkait ASI eksklusif, seperti Indonesia yang memiliki angka ASI eksklusif sebesar 30,4 persen dan kontinuitas ASI han ya 50,4 persen sampai usia dua tahun (P. Dewi et al., 2020).

Di negara-negara berkembang, praktik memberikan ASI telah melindungi kurang lebih 1,5 juta anak akibat kematian dan penyakit setiap tahun. Bayi yang baru lahir belum dapat sepenuhnya membentuk kekebalannya sendiri sampai beberapa bulan setelah lahir. Sebagai akibat dari bahan kimia imunologis tidak mampu diproduksi oleh anak, neonatus yang disusui cenderung tidak sakit, terutama di awal kehidupan. ASI mengandung berbagai komponen anti infeksi yangdapat menjaga anak dari infeksi bakteri, virus, dan jamur. Namun, kemampuan seorang ibu untuk memasok ASI kadang-kadang dapat terhambat. Batu sandungan terbesar adalah produksi susu yang tidak efisien (Rah madh an et al., 2013).

Kegagalan menyusui dapat disebabkan oleh berbagai keadaan. faktor demografi, sosial ekonomi, dan klinis sangat menentukan kontinuitas pemberian ASI. Beberapa penelitian didapatkan memberikan ASI eksklusif memiliki dampak jangka panjang terhadap ISPA, sembelit, diare, dan masalah lainnya. Proses persalinan seksio sesaria (SC) telah terbukti dua kali lebih mungkin mengakibatkan kegagalan menyusui. Promosi dan kepercayaan terhadap susu formula merupakan dua faktor eksternal yang sering menjadi penyebab kegagalan pemberian ASI eksklusif. Menurut laporan WHO, promosi susu formula yang agresif mengurangi minat ibu untuk menyusui (P. Dewi et al., 2020).

Kegagalan untuk memberikan ASI eksklusif dapat menyebabkan tingginya angka kejadian penyakit. Di Indonesia, hampir sembilan dari sepuluh ibu menyusui, namun studi Ikatan Dokter Anak Indonesia Salamah \& Prasetya (2019) mendapatkan bahwa sekitar 49,8\% wanita yang sukses pada ASI eksklusif selama enam bulan, seperti yang direkomendasikan oleh WHO. Hanya 32\% ibu di Jakarta yang melaksanakan ASI eksklusif, menurut penelitian yang dilakukan di DKI Jakarta oleh Program Magister Kedokteran Kerja, Departemen Kedokteran. Bahkan di Jakarta, hanya $80 \%$ pekerja manufaktur sukses terkait ASI eksklusif untuk anaknya. Kejadian ini diakibatkan oleh dukungan suami, pencapaian IMD, dan pekerjaan sebagai hasil dari aktivitas pekerjaan ibu yang berfokus pada karir (Salamah \& Prasetya, 2019).

Indonesia menempati peringkat 3 terakhir dari 51 negara di dunia dalam hal peraturan dan program pemberian makan bayi dan anak (Infant-Young Child Feeding) (IBFAN, 2014). Indonesia memiliki angka cakupan ASI eksklusif 61,33 persen. Persentase ini lebih besar dari target RENSTRA sebesar $44 \%$ untuk tahun 2017 (Kemenkes, 2018). 
Menurut Marifah (2019), peran pengetahuan ibu 57,9\%, dukungan pasangan $55.8 \%$, peran sikap ibu 69,5 persen, dan peran bidan 69,8\%. Menurut Wulandari (2013), pendidikan ibu berdampak 62 persen terhadap kegagalan pemberian ASI eksklusif, sedangkan pekerjaan ibu berdampak 76 persen. Selanjutnya terdapat karakteristik yang mempromosikan susu siap saji yang dapat menyebabkan kegagalan capaian ASI Ekslusif untuk anak umu nol sampai enam bulan, den gan odds ratio sebanyak 4.974 (Wulandari, 2011).

Prioritas pemimpin Indonesia dalam tercapainya status gizi, kesehatan maternal dan neonatal ditegaskan kembali dalam Undang-Undang Nomor 36 Tahun 2009 tentang Kesehatan. Menurut Pasal 128 UUD, setiap bayi berhak mendapatkan ASI eksklusif selama 6 (enam) bulan. Oleh karena itu, pemerintah bertanggung jawab menetapkan kebijakan untuk menjamin diperolehnya ASI eksklusif, sesuai dengan ketentuan pasal 129 (Lestari, 2021).

Sebagai bagian dari program peningkatan gizi bayi atau balita, Aceh khususnya Dinkes Kota Banda Aceh telah mendorong keberhasilan ASI eksklu sif selama 6 bulan seperti anjuran WHO. Di Indonesia yang sehat, sasaran program adalah agar setidaknya $80 \%$ ibu menyusui memberikan ASI eksklusif. Mencermati kebijakan Gubernur Aceh tentang ASI Eksklusif Nomor 49 Tahun 2016. Namun kebijakan itu belum dilaksanakan dengan baik oleh pemerintah setempat, dikarenakan Dinas Kesehatan Kota Banda Aceh masih menggunakan atau menerapkan aturan yang lama, padahal aturan baru yang telah diterapkan oleh gubernur untuk menyempurnakan kebijakan ASI eksklusif semakin baik. Dalam hal ini kebijakan tersebut belum terlaksana karena salah satu kendala di Dinas Kesehatan Kota Banda Aceh dalam melaksanakan kebijakan Asi Eksklusif ini belum terlaksana. Salah satu tokoh yang berperan penting dalam mengimplementasikan aturan yang dikeluarkan Pergub ini selalu bergantung pada hal tersebut, selama ini aturan tersebut belum dilaksanakan secara maksimal seperti yang diharapkan oleh masyarakat khususnya ibu-ibu yang sedang menyusui. Pasal 82 Undang-Undang (UU) Nomor 13 Tahun 2003 tentang Ketenagakerjaan merupakan kebijakan yang telah diambil oleh Dinas Kesehatan Kota Banda Aceh yang mengatur tentang cuti hamil. Cuti melahirkan berlangsung 1.5 bulan sebelum bayi lahir dan 1.5 bulan sesudah bayi lahir. Keperawatan eksklusif tidak memberikan hasil terbaik (Lestari, 2021).

Menurut laporan Dinas Kesehatan Kabupaten Pidie, persentase anak yang mendapat ASI Ekslusif pada 2017 yaitu 53\%, 59\% pada 2018, dan 66\% pada 2019, dengan target $80 \%$. Hal ini menunjukkan bahwa jumlah wanita yang menyusui secara eksklusif masih jauh lebih rendah dari yang diproyeksikan (Dinkes, 2014).

Jika dilihat dari pelaksanaannya yang diberikan tenaga medis, minimnya perhatian dan support terhadap pemberian ASI eksklusif oleh pemerintah daerah menjadi penyebab rendahnya dukungan ASI eksklusif di Kabupaten Pidie. Manajemen laktasi dan Inisiasi Menyusui Dini (IMD) dilaksanakan. Untuk mencapai Tujuan Pembangunan Berkelanjutan, salah satunya untuk membantu menurunkan angka kematian bayi, hal ini harus ditingkatkan (Mariana, 2021).

Penelitian ini yaitu untuk menganalisis penyebab gagalnya pencapaian ASI eksklusif bagi bayi di Rumah Sakit Tgk. Chik ditiro Pidie. 


\section{Metode Penelitian}

Jenis penelitian dengan survei analitik menggunakan pendekatan crossectional, dilaksanakan diruang kebidanan RSUD Tgk. Chik ditiro Kabupaten Pidie. Penelitian ini telah dilakukan pada tanggal 6 s/d 25 Mei 2021, objek penelitian semua ibu melahirkan dan menyusui diruang kebidanan yang berjumlah 85 orang sedangkan penggunaan sampel dilakukan secara total sampling sehingga jumlah sampel sebanyak 85 orang. Analisis data dengan langkah univariat, bivariat dan multivariat.

\section{Hasil}

\subsection{Analisis Univariat}

Dari 85 orang yang berdasarkan ASI Eksklusif didapatkan rata-rata bayi gagal terkait ASI Eksklusif sebanyak 56 orang (66\%), responden yang berumur 31 50 tahun yaitu 58 orang (68\%), mayoritas responden berpendidikan rendah yaitu 45 orang $(53 \%)$, rata-rata responden tidak bekerja yaitu 53 orang $(62 \%)$, mayoritas responden berpendapatan kurang yaitu 55 orang (65\%), paritas responden mayoritas multipara yaitu 60 orang $(71 \%)$, mayoritas usia bayi pada usia $0-2$ bulan yaitu sebanyak 58 orang (68\%), mayoritas responden berpengetahuan kurang baik yaitu 47 orang (55\%), mayoritas responden bersikap positif yaitu 57 orang $(67 \%)$, mayoritas responden memiliki perilaku tidak baik yaitu 47orang (55\%), bahwa mayoritas penolong persalinan tidak berperan yaitu 56 orang $(66 \%)$ dan mayoritas tidak mendukung yaitu 56 orang $(66 \%)$ dan variabel tradisi didapatkan bahwa mayoritas tidak mendukung yaitu 56 orang (66\%).

Table 1. Distribusi Frekuensi Pemberian ASI Ekslusif, Umur, Pendidikan, Pekerjaan, Pendapatan, Paritas, Usia Bayi, Pengetahuan, Sikap, Perilaku, Keterlibatan tenaga kesehatan dan Budaya

\begin{tabular}{cccc}
\hline No. & ASI Eksklusif & $\mathbf{f}$ & Persentase \\
\hline 1 & Ya & 29 & 34 \\
\hline 2 & Tidak & 56 & 66 \\
\hline & Total & 85 & 100 \\
\hline No & Umur lbu & $\mathbf{f}$ & Persentase \\
\hline 1 & 18-30 Th & 27 & 32 \\
\hline 2 & $31-50$ Thn & 58 & 68 \\
\hline & Total & 85 & 100 \\
\hline No & Pendidikan & $\mathbf{f}$ & Persentase \\
\hline 1 & Tinggi & 40 & 47 \\
\hline 2 & Rendah & 45 & 53 \\
\hline \multicolumn{5}{c}{ Total } & 85 & 100 \\
\hline No. & Pekerjaan & $\mathbf{f}$ & Persentase \\
\hline 1 & Bekerja & 32 & 38 \\
\hline 2 & Tidak Bekerja & 53 & 62 \\
\hline & Total & 85 & 100
\end{tabular}

\begin{tabular}{cccc}
\hline No. & Pendapatan & f & Persentase \\
\hline 1 & Cukup & 30 & 35 \\
\hline 2 & Kurang & 55 & 65 \\
\hline & Total & 85 & 100 \\
\hline
\end{tabular}




\begin{tabular}{|c|c|c|c|}
\hline Nomor & Paritas & $f$ & Persentase \\
\hline 1 & Primipara & 22 & 26 \\
\hline 2 & Multipara & 60 & 71 \\
\hline \multirow[t]{2}{*}{3} & Grande Multipara & 5 & 3 \\
\hline & Total & 85 & 100 \\
\hline No. & Usia Bayi & $f$ & Persentase \\
\hline 1 & $0-2$ Bulan & 58 & 68 \\
\hline \multirow[t]{2}{*}{2} & 3-6 Bulan & 27 & 32 \\
\hline & Total & 85 & 100 \\
\hline No. & Pengetahuan & $f$ & Persentase \\
\hline 1 & Baik & 38 & 45 \\
\hline \multirow[t]{2}{*}{2} & Kurang Baik & 47 & 55 \\
\hline & Total & 85 & 100 \\
\hline No. & Sikap & $f$ & Persentase \\
\hline 1 & Positif & 57 & 67 \\
\hline \multirow[t]{2}{*}{2} & Negatif & 28 & 33 \\
\hline & Total & 85 & 100 \\
\hline No. & Perilaku & $f$ & Persentase \\
\hline 1 & Baik & 38 & 45 \\
\hline \multirow[t]{2}{*}{2} & Tidak Baik & 47 & 55 \\
\hline & Total & 85 & 100 \\
\hline No. & Peran Penolong Persalinan & $\mathbf{f}$ & Persentase \\
\hline 1 & Berperan & 27 & 93 \\
\hline \multirow[t]{2}{*}{2} & Tidak Berperan & 2 & 3 \\
\hline & Total & 85 & 100 \\
\hline No. & Tradisi & f & Persentase \\
\hline 1 & Mendukung & 29 & 34 \\
\hline \multirow[t]{2}{*}{2} & Tidak Mendukung & 56 & 66 \\
\hline & Total & 85 & 100 \\
\hline
\end{tabular}

Sumber : Data Primer, 2021

\subsection{Analisis Bivariat}

Tabel 2. USia lbu dengan Pemberian ASIEksklusif Pada Bayi.

\begin{tabular}{|c|c|c|c|c|c|c|c|}
\hline \multirow{3}{*}{ Umur lbu } & \multicolumn{4}{|c|}{ Pemberian ASI Eksklusif } & \multirow{2}{*}{\multicolumn{2}{|c|}{ Jumlah }} & \multirow{3}{*}{$p$ (value) } \\
\hline & \multicolumn{2}{|c|}{$Y a$} & \multicolumn{2}{|c|}{ Tidak } & & & \\
\hline & $f$ & $\%$ & $f$ & $\%$ & $f$ & $\%$ & \\
\hline $18-30$ & 17 & 29 & 41 & 71 & 58 & 100 & \multirow{2}{*}{0,131} \\
\hline $31-50$ & 12 & 44 & 15 & 56 & 27 & 100 & \\
\hline Total & 29 & & 56 & & 85 & & \\
\hline
\end{tabular}

Data Primer, 2021

Temuan penelitian tentang hubungan usia ibu dengan ASI eksklusif pada bayi mengungkapkan bahwa 41 (58) dari 58 orang usia 18-30 tahun yang tidak memberikan ASI eksklusif pada bayi memiliki analisis uji statistik Chi-Square pvalue 0.131. > 0,05 menunjukkan bahwa tidak ada hubungan antara usia ibu dengan pemberian ASI eksklusif pada bayi. 
Tabel 3. Kaitan Pendidikan Ibu dengan Pemberian ASI Eksklusif Pada Bayi

\begin{tabular}{|c|c|c|c|c|c|c|c|}
\hline \multirow{3}{*}{ Pendidikan } & \multicolumn{4}{|c|}{ Pemberian ASI Eksklusif } & \multirow{2}{*}{\multicolumn{2}{|c|}{ Jumlah }} & \multirow{3}{*}{$p$ (value) } \\
\hline & \multicolumn{2}{|c|}{$Y a$} & \multicolumn{2}{|c|}{ Tidak } & & & \\
\hline & f & $\%$ & f & $\%$ & $f$ & $\%$ & \\
\hline Tinggi & 14 & 35 & 26 & 65 & 40 & 100 & \multirow{2}{*}{0,526} \\
\hline Rendah & 15 & 33 & 30 & 67 & 45 & 100 & \\
\hline Total & 29 & & 56 & & 85 & & \\
\hline
\end{tabular}

Sumber: Data Primer, 2021

Pendidikan dan pelaksanaan ASI eksklusif pada bayi memiliki nilai yang signifikan, yaitu 30 orang dari 45 orang dengan pendidikan rendah memberikan ASI eksklusif pada bayinya (45 persen). Analisis statistik Chi-Square menghasilkan $p=0,526$ sehingga tidak berhubungan antara sekolah terhadap suksesnya ASI eksklusif pada bayi.

Tabel 4. Hubungan Pekerjaan Ibu dengan Pemberian ASI Eksklusif.

\begin{tabular}{|c|c|c|c|c|c|c|}
\hline \multirow{3}{*}{ Pekerjaan } & \multicolumn{3}{|c|}{ Pemberian ASI Eksklusif } & \multirow{2}{*}{\multicolumn{2}{|c|}{ Jumlah }} & \multirow{3}{*}{$p$ (value) } \\
\hline & $Y a$ & \multicolumn{2}{|c|}{ Tidak } & & & \\
\hline & $\%$ & $f$ & $\%$ & $f$ & $\%$ & \\
\hline Bekerja & 1134 & 21 & 66 & 32 & 100 & \\
\hline Tidak Bekerja & 1834 & 35 & 66 & 53 & 100 & 5/6 \\
\hline Total & 29 & 56 & & 85 & & \\
\hline
\end{tabular}

Sumber: Data Primer, 2021

Terdapat hasil yang signifikan pekerjaan dan pemberian ASI eksklusif, dari 53 responden, 35 di antaranya tidak bekerja dan tidak memberikan ASI eksklusif pada bayinya (66 persen). P-value $=0,576$ hal tersebut bahwa tidak ada pengaruh pekerjaan terhadap ASI eksklusif.

Tabel 5. Hubungan Pendapatan lbu dengan Pemberian ASI Eksklusif Terhadap Bayi.

\begin{tabular}{|c|c|c|c|c|c|c|c|}
\hline \multirow{3}{*}{ Pendapatan } & \multicolumn{4}{|c|}{ ASI Eksklusif } & \multirow{2}{*}{\multicolumn{2}{|c|}{ Jumlah }} & \multirow{3}{*}{$p$ (value) } \\
\hline & \multicolumn{2}{|c|}{$Y a$} & \multicolumn{2}{|c|}{ Tidak } & & & \\
\hline & $f$ & $\%$ & $f$ & $\%$ & $f$ & $\%$ & \\
\hline Cukup & 12 & 40 & 18 & 60 & 30 & 100 & \multirow{2}{*}{0,576} \\
\hline Kurang & 11 & 31 & 38 & 69 & 55 & 100 & \\
\hline Total & 29 & & 56 & & 85 & & \\
\hline
\end{tabular}

Sumber: Data Primer, 2021

Hubungan pendapatan terhadap ASI Eksklusif pada bayi menunjukkan bahwa dari 53 responden yang berpendapatan kurang mayoritas juga tidak memberikan ASI Eksklusif pada bayi yaitu 38 orang (55\%). Nilai p-value $=0,271$ dimana tidak berkaitan antara pendapatan dengan pemberian ASI Eksklusif pada bayi.

Tabel 6. Hubungan Paritas Ibu dengan Pemberian ASIEksklusif Untuk Bayi.

\begin{tabular}{|c|c|c|c|c|c|c|c|}
\hline \multirow{3}{*}{ Paritas } & \multicolumn{4}{|c|}{ Pemberian ASI Eksklusif } & \multirow{2}{*}{\multicolumn{2}{|c|}{ Jumlah }} & \multirow{3}{*}{$p$ (value) } \\
\hline & $\bar{Y}$ & & Tida & & & & \\
\hline & $f$ & $\%$ & $f$ & $\%$ & $f$ & $\%$ & \\
\hline Primipara & 7 & 32 & 15 & 68 & 22 & 100 & 0,477 \\
\hline
\end{tabular}




\begin{tabular}{lcccccc}
\hline Multipara & 20 & 33 & 40 & 67 & 60 & 100 \\
\hline $\begin{array}{l}\text { Grande } \\
\text { Multipara }\end{array}$ & 2 & 67 & 1 & 33 & 3 & 100 \\
\hline \multicolumn{1}{c}{ Total } & $\mathbf{2 9}$ & & $\mathbf{5 6}$ & \multicolumn{8}{c}{$\mathbf{8 5}$} \\
\hline
\end{tabular}

Sumber: Data Primer, 2021

Hubungan paritas dengan pemberian ASI Eksklusif pada bayi menunjukkan bahwa dari 60 responden dengan katagori multipara mayoritas tidak memberikan ASI Eksklusif pada bayi yaitu 40 orang (67\%). Angka $p=0,477$ yang artinya tidak ada hubungan antara paritas dengan pemberian ASI Eksklusif pada bayi.

Tabel 7. Hubungan Usia Bayi dengan Pemberian ASIEksklusif .

\begin{tabular}{|c|c|c|c|c|c|c|c|}
\hline \multirow{3}{*}{ Usia Bayi } & \multicolumn{4}{|c|}{ Pemberian ASI Eksklusif } & \multirow{2}{*}{\multicolumn{2}{|c|}{ Jumlah }} & \multirow{3}{*}{$p$ (value) } \\
\hline & \multicolumn{2}{|c|}{$Y a$} & \multicolumn{2}{|c|}{ Tidak } & & & \\
\hline & f & $\%$ & $f$ & $\%$ & $f$ & $\%$ & \\
\hline $0-2$ Bulan & 20 & 34 & 38 & 66 & 58 & 100 & \\
\hline 3-6 Bulan & 9 & 33 & 18 & 67 & 27 & 100 & 0,560 \\
\hline Total & 29 & & 56 & & 85 & & \\
\hline
\end{tabular}

Sumber: Data Primer, 2021

Umur bayi dikaitkan dengan pemberian ASI eksklusif pada bayi baru lahir mengungkapkan bahwa 38 responden mendukung pemberian ASI eksklu sif pada bayi (66 persen). Nilai p 0,560 > 0,05 menunjukkan bahwa tidak ada hubungan antara usia bayi dengan pemberian ASI eksklusif.

Tabel 8. Hubungan Pengetahuan dengan Pemberian ASI Eksklusif Pada Bayi.

\begin{tabular}{|c|c|c|c|c|c|c|c|}
\hline \multirow{3}{*}{ Pengetahuan } & \multicolumn{4}{|c|}{ Pemberian ASI Eksklusif } & \multirow{2}{*}{\multicolumn{2}{|c|}{ Jumlah }} & \multirow{3}{*}{$p$ (value) } \\
\hline & \multicolumn{2}{|c|}{ Ya } & \multicolumn{2}{|c|}{ Tidak } & & & \\
\hline & $f$ & $\%$ & $\mathbf{f}$ & $\%$ & $f$ & $\%$ & \\
\hline Baik & 24 & 63 & 14 & 37 & 38 & 100 & \\
\hline Kurang & 5 & 11 & 42 & 89 & 47 & 100 & 0,000 \\
\hline Total & 29 & & 56 & & 85 & & \\
\hline
\end{tabular}

Sumber : Data Primer, 2021

Hubungan pengetahuan dengan pemberian ASI Eksklusif pada bayi menunjukkan bahwa dari 47 orang pada katagori pengetahuan kurang mayoritas tidak melakukan ASIEksklusif pada bayi yaitu 42 orang (89\%) dan Uji Chi-Square didapatkan hasil $p$-value $=0,000>\alpha$ 0,05 yang artinya ada hubungan antara pengetahuan dengan pemberian ASI Ekslusif.

Tabel 9. Hubungan Sikap dengan Pemberian ASIEksklusif Pada Bayi.

\begin{tabular}{|c|c|c|c|c|c|c|c|}
\hline \multirow{3}{*}{ Sikap } & \multicolumn{4}{|c|}{ Pemberian ASI Eksklusif } & \multirow{2}{*}{\multicolumn{2}{|c|}{ Jumlah }} & \multirow{3}{*}{$p$ (value) } \\
\hline & \multicolumn{2}{|c|}{$Y a$} & \multicolumn{2}{|c|}{ Tidak } & & & \\
\hline & $f$ & $\%$ & $f$ & $\%$ & $f$ & $\%$ & \\
\hline Positif & 27 & 47 & 30 & 53 & 57 & 100 & \multirow{2}{*}{0,131} \\
\hline Negatif & 2 & 7 & 26 & 93 & 28 & 100 & \\
\hline Total & 29 & & 56 & & 85 & & \\
\hline
\end{tabular}

Sumber: Data Primer, 2021

Kaitan variabel sikap dan capaian ASI Eksklusif pada bayi menunjukkan bahwa dari 57 responden yang bersikap positif mayoritas tidak memberikan ASI 
Eksklusif pada bayi yaitu 30 orang (53\%). Nilai $p$-value $=0,000<\alpha 0,05$ yang artinya ada hubungan antara sikap dengan pemberian ASI Eksklu sif pada bayi.

Tabel 10. Hubungan Perilaku lbu dengan Pemberian ASI Eksklusif.

\begin{tabular}{|c|c|c|c|c|c|c|c|}
\hline \multirow{3}{*}{ Perilaku Ibu } & \multicolumn{4}{|c|}{ Pemberian ASI Eksklusif } & \multirow{2}{*}{\multicolumn{2}{|c|}{ Jumlah }} & \multirow{3}{*}{$p$ (value) } \\
\hline & \multicolumn{2}{|c|}{$Y a$} & \multicolumn{2}{|c|}{ Tidak } & & & \\
\hline & $f$ & $\%$ & $f$ & $\%$ & $f$ & $\%$ & \\
\hline Baik & 14 & 37 & 24 & 63 & 38 & 100 & \\
\hline Tidak Baik & 15 & 32 & 32 & 68 & 47 & 100 & 2 \\
\hline Total & 29 & & 56 & & 85 & & \\
\hline
\end{tabular}

Sumber : Data Primer, 2021

Hubungan antara perilaku dalam memberikan ASI Eksklusif pada bayi menunjukkan bahwa dari 47 responden yang berperilaku tidak baik mayoritas tidak memberikan ASI Eksklusif pada bayi yaitu 32 orang (47\%). Selanjutnya didapatkan nilai $p$-value $=0,402>\alpha 0,05$ yang artinya tidak ada hubungan antara perilaku dengan pemberian ASI Eksklusif pada bayi.

Tabel 11. Hubungan Peran Penolong Persalinan dengan Pemberian ASI Eksklusif

\begin{tabular}{|c|c|c|c|c|c|c|c|}
\hline \multirow{3}{*}{$\begin{array}{l}\text { Peran Penolong } \\
\text { Persalinan }\end{array}$} & \multicolumn{4}{|c|}{ Pemberian ASI Eksklusif } & \multirow{2}{*}{\multicolumn{2}{|c|}{ Jumlah }} & \multirow{3}{*}{$p$ (value) } \\
\hline & \multicolumn{2}{|c|}{$Y a$} & \multicolumn{2}{|c|}{ Tidak } & & & \\
\hline & $f$ & $\%$ & $f$ & $\%$ & $f$ & $\%$ & \\
\hline Berperan & 27 & 93 & 2 & 7 & 29 & 100 & \\
\hline Tidak Berperan & 2 & 3 & 54 & 97 & 56 & 100 & 0,000 \\
\hline Total & 29 & & 56 & & 85 & & \\
\hline
\end{tabular}

Sumber: Data Primer, 2021

Adanya hubungan peran bidan dengan ASI Eksklusif pada bayi menunjukkan bahwa dari 56 responden mayoritas penolong persalinan tidak berperan pada pelaksanaan ASI Eksklusif pada bayi yaitu 54 orang (97\%). Nilai pvalue $=0,000$ sehingga ada hubungan antara peran penolong persalinan dengan pemberian ASI Eksklusif pada bayi.

Tabel 12. Hubungan Tradisi dengan Pemberian ASI Eksklusif kepada Bayi.

\begin{tabular}{|c|c|c|c|c|c|c|c|}
\hline \multirow{3}{*}{ Tradisi } & \multicolumn{4}{|c|}{ Pemberian ASI Eksklusif } & \multirow{2}{*}{\multicolumn{2}{|c|}{ Jumlah }} & \multirow{3}{*}{$p$ (value) } \\
\hline & \multicolumn{2}{|c|}{$Y a$} & \multicolumn{2}{|c|}{ Tidak } & & & \\
\hline & $\mathbf{f}$ & $\%$ & $f$ & $\%$ & $f$ & $\%$ & \\
\hline Mendukung & 21 & 72 & 8 & 28 & 29 & 100 & \\
\hline Tidak Mendukung & 8 & 14 & 48 & 86 & 56 & 100 & 1,000 \\
\hline Total & 29 & & 56 & & 85 & & \\
\hline
\end{tabular}

Sumber : Data Primer, 2021

Hubungan tradisi terhadap suksesnya ASI Eksklusif untuk bayi menunjukkan bahwa dari 56 orang mayoritas tidak didukung oleh tradisi dalam pemberian ASI Eksklusif pada bayi yaitu 48 orang (86\%). Hasil p-value $=0,000<\alpha 0,05$ yang artinya ada hubungan antara tradisi dengan pemberian ASI Eksklusif pada bayi. 


\subsection{Analisis Multivariat}

\section{1) Model Summary}

Tabel 13. Model Sumary

\begin{tabular}{ccccc}
\hline Md & $\boldsymbol{R}$ & R Square & Adjusted R Square & $\begin{array}{c}\text { Std. Error of } \\
\text { The Estimate }\end{array}$ \\
\hline 1 & $933^{\mathrm{a}}$ & .871 & .851 & .184 \\
\hline
\end{tabular}

Dari tabel diatas dapat diuraikan sebagai berikut:

a. Hasil $R$ yaitu $.933^{a}$ terlihat korelation dengan variabel bebas (umur ibu, pendidikan, pekerjaan, pendapatan, paritas, usia bayi, pengetahuan, sikap, perilaku, variabel bebas (ASI eksklusif) dibandingkan dengan variabel terikat (penolong persalinan dan tradisi) sangat bermakna.

b. R Square .871 berarti variabel independen (umur ibu, pendidikan, pekerjaan, pendapatan, paritas, usia bayi, pengetahuan, sikap, perilaku, penolong persalinan dan tradisi) mendapatkan keterkaitan sebesar $85,10 \%$ terhadap variable dependen (ASl eksklusif).

\section{2) Anova (Uji F/Uji Serempak)}

Uji $F$ didaptkan yaitu 44.785 dan signifikan ,000. Dimana propabilitas $0,000<$ dari $0.05(p=0,05)$ maka secara serempak (Uji $F)$ terdapat pengaruh antara variabel umur ibu, pendidikan, pekerjaan, pendapatan, paritas, usia bayi, pengetahuan, sikap, perilaku, petugas kesehatan dan kebiasaan dengan pelaksanaan ASI eksklusif sebagai berikut:

Tabel 14. Annova

\begin{tabular}{lcclcc}
\hline Model & Sum of Square & $\boldsymbol{d r}$ & Mean Square & $\boldsymbol{F}$ & Sig. \\
\hline 1 Regression & 16,640 & 11 & 1,513 & $44.7850,000^{\mathrm{a}}$ \\
\hline Residual & 2,466 & 73 & & \\
\hline Total & 19,106 & 84 & & & \\
\hline
\end{tabular}

\section{3) Coeficient (Uji t/Uji Partial)}

Tabel 15. Coefficient

\begin{tabular}{lccccc}
\hline Model & $\boldsymbol{B}$ & $\begin{array}{c}\text { Std. } \\
\text { Error }\end{array}$ & Beta & $\boldsymbol{t}$ & Sig \\
\hline 1 (Constant) & -.162 & .102 & & -1.590 & .116 \\
\hline Umur lbu & -.052 & .046 & .051 & -1.135 & .260 \\
\hline Pendidikan & .045 & .075 & .047 & .594 & .554 \\
\hline Pekerjaan & -.095 & .108 & .097 & .881 & .381 \\
\hline Pendapatan & .099 & .083 & .100 & 1.198 & .235 \\
\hline Paritas & .048 & .044 & .050 & 1.104 & .273 \\
\hline Usia Bayi & .039 & .047 & .038 & .825 & .412 \\
\hline Pengetahuan & .158 & .046 & .166 & 3.423 & .001 \\
\hline Sikap & .029 & .047 & .029 & .611 & .543 \\
\hline Perilaku & .058 & .048 & .061 & 1.220 & .226 \\
\hline Penolong & .720 & .058 & .720 & 12.412 & .000 \\
Persalinan & & & & & .003 \\
\hline Tradisi & .171 & .056 & .171 & 3.054 & \\
\hline
\end{tabular}



yaitu :

Kesesuaian regresi yang didapatkan berdasarkan tabel Coefficient diatas

$Y=-.162+-.052 X 1+.045 X 2+-.095 X 3+.099 X 4+.048 X 5+.039 X 6+$ $.158 \times 7+.029 \times 8+.058 \times 9+.720 \times 10+.171 \times 11$

Penjelasan tabel Coeficient diatas diu raikan berikut ini :

Dari hasil tabel Coefficient untuk variabel umur ibu, pendidikan, pekerjaan, pendapatan, paritas, usia bayi, pengetahuan, sikap, perilaku, penolong persal inan dan tradisi dalam pemberian ASI eksklusif dengan nilai sig 0,116 > dari $p: 0,05$; artinya tidak terdapat pengaruh signifikan variabel umur ibu, pendidikan, pekerjaan, pendapatan, paritas, usia bayi, pengetahuan, sikap, perilaku, penolong persalinan dan tradisi .

\section{Pembahasan}

\subsection{Hubungan Umur lbu dengan Pemberian ASI Eksklusif pada Bayi}

Hasil penelitian yaitu p-value 0,131. Menurut penelitian Ryan et al, ibu usia 31-50 tahun memiliki prevalensi ASI eksklusif lebih tinggi dan durasi menyusui lebih lama selama 6 bulan. Menurut temuan Bayley et alstudy, semakin tua usia ibu maka akan mempunyai sikap yang lebih baik terhadap menyusui. Sikap positif berdampak pada faktor psikologis. Ibu muda sering mengungkapkan rasa malu tentang menyusui dan mempertahankan bentuk payudara; Selain itu, banyak ibu muda saat ini bekerja di kantor dan ragu untuk memberikan ASI eksklusif karena keterbatasan waktu (Untari, 2017).

Usia di bawah 18-30 tahun merupakan masa reproduktif yang sehat dan matang sehingga mampu sangat mendukung untuk memberikan ASI yang khas, sedangkan usia 31-50 tahun, meskipun sudah mendapatkan status gizi yang sesuai, namun pada Usia tersebut dianggap berbahaya, karena masing-masing organ reproduksi dan kerangka ibu sudah ada. banyak berkurang dan berkurang, kecuali bahwa mungkin ada kemungkinan terbawa oleh anak dan juga dapat masalah pertumbuhan pada kehamilan, persalinan dan nifas.

\subsection{Pendidikan Ibu dengan Pemberian ASI Eksklusif Pada Bayi.}

Hasil penelitian di peroleh nilai p-value 0,526. Derajat pendidikan, menurut Notoatmodjo, merupakan jenjang pendidikan yang paling layak pada akhirnya. Derajat pendidikan seseorang merupakan ukuran kemampuannya untuk melakukan secara ilmiah. Pesan atau informasi yang disajikan akan sulit dipahami oleh seseorang yang tingkat pengetahuannya rendah.

Meskipun gagasan di atas menjelaskan bagaimana perempuan dengan tingkat pendidikan yang tinggi atau baik dapat mengambil semua informasi dengan lebih mudah. Penelitian sebelumnya didapatkan dengan tingginya pendidikan, semakin banyak ibu yang tidak menyusui anaknya. Keadaan ini sama dengan temuan Soenardi yang menunjukkan bahwa dengan semakin meningkatnya keterlibatan dan emansipasi perempuan di semua ranah kerja dan kebutuhan masyarakat, demikian pula keinginan mereka untuk menyusui dan menyusui anaknya (Pitaloka et al., 2018).

Karena ibu harus bekerja dan ibu tidak tahu cara mempertahankan ASI secara efektif, ibu dengan pendidikan tinggi menyusui bayinya secara ekslusif. 


\subsection{Hubungan Pekerjaan Ibu dengan Pemberian ASI Eksklusif Pada Bayi.}

Temuan penelitian ini diberi nilai p 0,576 . Hal ini menunjukkan bahwa wan ita pekerja menghadapi tantangan seperti waktu persalinan yang terlalu singkat dan kurangnya ruang menyusui. Ibu bekerja yang sedang menyusui tidak perlu berhenti; Sebaliknya, mereka harus terus menyusui bayinya secara eksklusif sampai mereka mencapai usia enam bulan. PP No. 33 Tahun 2012 memuat sejumlah kemudahan yang memungkinkan ibu untuk memberikan ASI eksklusif selama bekerja (Pitaloka et al., 2018).

Selanjutnya, lingkungan sosial merupakan faktor yang harus diperhatikan. Masih ada beberapa usaha yang tidak mengizinkan pemberian ASI, sehingga menambah beban ibu bekerja untuk dapat menyusui atau memerah ASInya. Volume ASI yang diperah dapat dipengaruhi oleh jumlah tekanan yang diberikan pada ibu. Alhasil, salah satu manfaat ASI eksklusif adalah dukungan lingkungan, yang membuat ibu menyusui merasa nyaman dan memastikan aliran ASI lancar.

Penerimaan adalah komponen penting untuk menumbuhkan kesadaran diri untuk menumbuhkan motivasi positif selama proses keperawatan. Menurut teori motivasi perlindungan yang dikemukakan oleh Darwis dan Hikmawati dalam bukunya Kesehatan Masyarakat dalam Perspektif Sosio-antropologi, didasarkan pada empat faktor: keseriusan, kemungkinan terjadinya, atau kerentanan, efektivitas perilaku, pencegahan yang direkomendasikan, dan keyakinan. dalam kemampuan seseorang. Hal ini akan meningkatkan kepercayaan diri ibu, menjadikan menyusui sebagai pengalaman yang lebih menyenangkan dan memastikan bahwa bayi mendapat ASI yang memadai sehingga ia mencapai usia dua tahun (Sutrini \& Aulia, 2020).

\subsection{Hubungan Pendapatan Ibu dengan Pemberian ASI Eksklusif Pada Bayi}

Hasil penelitian dengan p-value 0,271. Hal ini menunjukkan bahwa wanita berpenghasilan rendah lebih mungkin dapat memberikan ASI secara ekslusif. Salah satu unsur yang mempengaruhi pola menyusui adalah status ekonomi keluarga. Masalah ini cukup asli di tempat-tempat pedesaan; semakin tinggi tingkat ekonomi semakin rendah prevalensinya, karena mampu memberikan susu formula dan statusnya meningkat (Eugenie et al., 2015).

Demikian pula dengan hasil Riset Kesehatan Dasar (Riskesdas) tentang ASI Eksklusif, yang menunjukkan hubungan yang jelas antara ASI Eksklusif dengan pengeluaran per kapita. Pada kelompok bayi usia 0-1 bulan, 2-3 bulan, dan 4-5 bulan, semakin tinggi pengeluaran per kapita keluarga maka semakin rendah angka pemberian ASl eksklusif (Wulansari \& Pramono, 2014).

\subsection{Keterkaitan Paritas terhadap Pelaksanaan ASI Eksklusif Pada Bayi.}

Pada variabel ini didapatkan nilai p 0,477. Hal ini menunjukkan bahwa paritas ibu terkait dengan pengalaman melahirkan ibu. Multipara adalah yang paling aman bagi ibu. Sementara itu, kesehatan ibu memburuk dengan cepat pada persalinan ketiga dan selanjutnya. Dapat kita lihat bahwa ibu yang memberika ASi kepada anak ke 3 dan ke 4 , ibu yang menyusui anak pertama memiliki proses menyusui yang kurang memadai. Untuk mendapatkan pemahaman yang lebih baik tentang manajemen laktasi, perlu untuk mendapatkan pengalaman. Dalam skenario ini, pengalaman seorang ibu didasarkan pada jumlah anak yang dilahirkannya. ASI 
lebih mungkin diberikan kepada bayi oleh ibu yang memiliki lebih dari satu anak (Syafneli \& EY, 2015).

Dari penelitian tersebut diketahui bahwa pemberan ASI Eksklusif tidak berkaitan dengan jumlah paritas, namun di dukung dengan adanya faktor lain seperti masalah kesehatan, masalah pekerjaan, ASI tidak keluar dan lain-lain sehingga apabila ibu mengalami hal tersebut meskipun memilki anak pertama atau lebih dapat meningkatkan kegagalan pelaksanaan ASI secara Ekslusif.

\subsection{Hubungan Usia Bayi dalam Pemberian ASI Eksklusif Pada Bayi}

Temuan penelitian ini diberi nilai $\mathrm{p} 0,560$. Menyusui sangat penting untuk perkembangan fisik dan mental yang optimal, serta untuk IQ bayi. Oleh karena itu, pemberian ASI memerlukan perhatian ibu dan tenaga kesehatan agar proses menyusui berhasil dilakukan.

Karena faktor-faktor seperti 51,72\% karena bayi menangis dan mengeluh, dan 27,59\% karena bayi masih lapar, maka pemberian ASI eksklusif oleh ibu usia 6 bulan tidak ada kaitannya. Agar ibu sadar bahwa kondisi bayinya terus-men erus menangis dan kegembiraan yang diciptakan bayi masih lapar, ibu terpaksa memberikan makanan pendamping sebelum bayi mencapai usia enam bulan. Meskipun faktanya bayi menangis sepanjang waktu, bukan karena lapar, tetapi karena berbagai alasan seperti rasa terganggu dan sebagainya. Lebih lanjut, 17,3 persen ibu menyebutkan produksi ASI yang rendah menjadi alasan tidak bisa memberikan ASI eksklusif kepada bayinya karena ASInya belum keluar. Banyaknya ibu yang menyusui secara teratur pada kenyataannya akan meningkatkan jumlah ASI yang diproduksi oleh ibu.

Hal yang paling memprihatinkan adalah sering ditemukan di posyandu bahwa setiap ibu yang datang ke posyandu mendapatkan makanan pendamping ASI berupa biskuit dan susu kemasan yang merupakan sumbangan komersial. Kalaupun bidan desa tidak suka saat ibu menyusui memberikan makanan lain pada bayi saat ia berusia 6 bulan, kemungkinan makanan tersebut diberikan kepada bayi saat ia kembali ke rumah. Akibatnya, besar kemungkinan menjadi penyebab serta kendala bagi ibu untuk memenuhi ASI eksklusif untuk anaknya (Jannah, 2016).

\subsection{Hubungan Pengetahuan Ibu dengan Pemberian ASI Eksklusif Pada Bayi}

Hasil penelitian di peroleh nilai $p$-value 0,000. Pernyataan tersebut menyatakan bahwa pengetahuan seorang ibu berpengaruh dengan pendidikan, sehingga akan mempengaruhi sikap dan berdampak pada perilaku, khususnya perilaku dalam spemberian ASI eksklusif pada anaknya. Sementara ASI tidak perlu dibeli dan sangat bermanfaat bagi tumbuh kembang anak, ibu tidak menghargai ASI eksklusif karena kurangnya pengetahuan.

Menurut (Purwanto et al., 2020) wanita yang memiliki pengetahuan yang kurang tentang ASI eksklusif memiliki perilaku yang kurang baik dalam memberikan ASI eksklusif, dan pemberian ASI pengganti dapat membantu ibu dan bayi, sehingga ibu tidak memberikan ASI eksklusif kepada bayinya (Mariana, 2021). 


\subsection{Sikap lbu dan Pemberian ASI Eksklusif Pada Bayi.}

Positifnya prilaku ibu terhadap ASI eksklusif, memungkinkannya menjadi pendukung yang berpengaruh signifikan terhadap pelaksanaan praktik tersebut. Salah satu sikap negatif yang mempengaruhi cara ini adalah ibu yang percaya bahwa susu formula lebih unggul dari ASI. Keyakinan bahwa apa yang diberikan kepada anak adalah yang terbaik mendorong pengambilan keputusan untuk memilih menyusui dan berusaha untuk mempraktekkannya dengan sukses. Sikap tidak dipengaruhi oleh jumlah anak atau frekuensi melahirkan.

Sikap dipengaruhi dengan berbagai aspek, seperti pengalaman pribadi, pengaruh orang penting lainnya, budaya, media massa, lembaga pendidikan, dan lembaga keagamaan, serta faktor emosional. Penyuluhan yang baik akan berdampak baik dan lebih bermanfaat bagi responden sehingga terjadi peningkatan pemberian ASI eksklusif (Mariana, 2021).

Terdapat kondisi-kondisi tertentu dimana meskipun ibu bersikap positif namun ibu tetap tidak mau memberi ASI Eksklusif seperti ASI tidak keluar, kesibukan pekerjaan dan sebagainya, belum tentu sikap terwujud dalam suatu tindakan. Terwujudnya sikap agar menjadi tindakan nyata diperlukan dukungan dari pihak tertentu seperti tenaga kesehatan, keluarga atau orang-orang terdekat ibu (Haurissa et al., 2019).

\subsection{Hubungan Perilaku Ibu dengan Pemberian ASI Eksklusif Pada Bayi}

Sebuah p-nilai 0,560 ditugaskan untuk temuan penelitian. Menyusui sangat penting untuk menunjang kesehatan tubuh mental bayi yang optimal, serta kepintarannya. Oleh karena itu, pemberian ASI memerlukan perhatian baik ibu maupun tenaga kesehatan agar dapat terlaksana dengan baik.

Karena alasan seperti 51,72 persen karena bayi menangis dan mengeluh, dan 27,59 persen karena bayi masih lapar, pemberian ASI eksklusif oleh ibu usia enam bulan tidak ada kaitannya. Agar ibu mengetahui kondisi bayi (menangis terus-menerus) dan kegembiraan yang ditimbulkan oleh rasa lapar bayi, ibu didorong agar mengganti ASI dengan makanan lain sebelum bayi mencapai usia enam bulan. Meskipun bayi menangis sepanjang waktu karena berbagai alasan, termasuk rasa tidak aman, tidak nyaman, sakit, dan sebagainya, mereka melakukannya karena lapar. Lebih lanjut, 17,3 persen ibu menyebutkan produksi ASI yang rendah menjadi alasan ibu enggan meyu sui karena ASInya belum keluar. Faktanya jumlah ibu yang menyusui seringkali meningkatkan produksi ASI ibu.

Hal yang paling memprihatinkan adalah di posyandu sering ditemukan bahwa para ibu-ibu yang datang ke posyandu memperoleh makanan pendamping ASI seperi biskuit dan susu kemasan yang disalurkan dari sumbangan komersial. Meskipun bidan desa tidak suka ibu menyusui memberikan makanan lain kepada bayinya ketika dia berusia 6 bulan, mungkin saja makanan itu diberikan kepada bayinya ketika dia kembali ke rumah. Akibatnya, tidak menutup kemungkinan hal ini menjadi kendala bagi ibu yang ingin memberikan ASl eksklusif (Untari, 2017).

\subsection{Hubungan Peran Penolong Persalinan dengan Pelaksanaan ASI Eksklusif Pada Bayi}

Bidan mempunyai kontribusi yang kuat terhadap keberhasilan pemberian ASI secara eklusif. Dengan adanya emberitahuan dari bidan maka ibu akan belajar 
menyusui bayinya. Penolong persalinan ikut memberikan kontribusinya kepada ibu-ibu dalam pemberian ASI Eksklusif kepada bayinya (Sholikah, 2018).

Pendampingan adalah kunci utama pemenuhan ASI eksklusif dan pencegahan pemberian makanan pralakteal. Hal ini dikarenakan pada saat bayi baru lahir, posisi penolong persalinan bisa sangat dominan, khususnya dalam istilah IMD yang merupakan salah satu standar keberhasilan menyusui.

Secara keseluruhan lukisan yang dicapai dengan bantuan bidan bisa sangat ampuh dalam menumbuhkan pemahaman ibu hamil tentang satu-satunya cara menyusui dan manajemen laktasi. Oleh karena itu, melalui pemahaman yang benar tentang menyusui yang unik dengan dorongan dan bantuan dari pen olong persalinan, ibu menyusui menjadi saran untuk menawarkan ASI eksklusif kepada bayinya (Jannah, 2016).

\subsection{Hubungan Tradisi terhadap Pemberian ASI Eksklusif Pada Bayi}

Hasil penelitian di peroleh nilai sig. p-value 0,000. Maknanya yaitu terdapat pengaruh tradisi dengan pemberian ASI eksklusif pada ibu menyusui. Penelitian yang dilakukan oleh Setyaningsih \& Farapti (2018), mengenai hubungan kepercayaan dan tradisi keluarga pada ibu menyusui dengan pemberian ASI eksklusif yang menyimpulkan bahwa terdapat keterkaitan antara kepercayaan dan tradisi. Dengan adanya tradisi maka akan mempengaruhi perilaku masyarakat untuk menyesuaikan diri dengan tradisi yang ada di lingkungannya. Praktik membuang cairan kolostrum saat menyusui, yang didasari anggapan bahwa kolostrum dalam ASI berbahaya bagi bayi, tetap menjadi salah satu manfaat ASI ekslusif.

Tradisi muncul untuk mempengaruhi perilaku masyarakat untuk menyesuaikan diri dengan tradisi yang ada di lingkungannya. Mitos adalah hal-hal yang menghambat pemberian ASI secara alamiah. Beberapa mitos yang umum adalah bahwa kolostrum yang terkandung dalam ASI buruk dan berbah aya bagi bayi, bahwa diperlukan teh atau cairan khusus sebelum menyusui, dan bahwa bayi akan mengalami kekurangan gizi jika hanya diberikan ASI. Tradisi yang berkembang dimasyarakat mengikuti tradisi yang biasa dilakukan keluarga meskipun berbeda dengan saran dari petugas kesehatan seperti memberikan madu, air, yang manis atau air kelapa untuk bayi kurang dari 6 bulan, memberikan makanan sejak dini seperti pisang dan bubur pada anak sebelum berusia 6 bulan dan adanya pemberian MP-ASI sejak dini dengan alasan bayi tidak rewel, tidak kelaparan dan selalu menangis (T. Dewi, 2021).

\section{Kesimpulan}

Berdasarkan hasil penelitian dan analisa data penyebab gagalnya pencapaian ASI eksklusif bagi bayi, maka dapat ditarik kesimpulan yaitu Adanya hubungan pengetahuan, sikap, peran penolong, tradisi dengan pemberian ASI eksklusif pada bayi serta diperoleh hasil variabel sangat dominan mempengaruhi pemberian ASI eksklusif yaitu variabel peran penolong persalinan. Dengan demikian, perlu dilakukanpenelitian Ianjutan guna memperdalam hasil penelitian demi tercapainya cakupan pemberian ASI sehingga dapat meningkatkan kesejahteraan bayi. Sehingga penelitian ini juga dapat membantu dan menemukan inovasi-inovasi terbaru baik bagi petugas kesehatan maupun bayi ibu menyusui. Selanjutnya diperlukan peran aktif dari tenaga kesehatan guna mendukung dan 
memberikan motivasi kepada masyarakat untuk memenuhi kebutuhan bayinya melalui pemberian ASI eksklusif dengan memberikan edukasi dan informasi melalui kegiatan konseling dan penyuluhan yang berkelanjutan kepada masyarakat dan kepada ibu-ibu khususnya dalam rangka meningkatkan partisipasi mereka dalam memberikan ASI kepada bayinya.

\section{Daftar Pustaka}

Dewi, P., Watinngsih, A., Megaputri, P., Dwijayanti, L., Jayanti, N., \& Wahyuni, I. (2020). Pediktor Kegagalan Pemberian ASI Eksklkusif Di Wilayah Kerja Puskesmas Spaten Buleleng. J Lmah Bidan, 1.

Dewi, T. (2021). Pengetahuan, keyakinan dan budaya lbu Menyusu Berkaitan terhadap ASI Eksklusif. Jurnal Keperawatan, 13(1), 213-226.

Dinkes. (2014). Situasi dan Analaisis ASI Eksklusif.

Eugenie, T., Batlejeri, J., \& Napitupulu, M. (2015). Pengetahuan ibu merupakan Faktor Dominan dalam Pemberian Asi Eksklusif. Jurnal IImu Dan Teknologi Kesehatan, 2(2), 27-33.

Haurissa, T., Manueke, I., \& Kusmiyati, K. (2019). Pengetahuan dan Sikap Ibu Menyusui dengan Perilaku Pemberian ASI Eksklusif. JIDAN: Jurnal IImiah Bidan, 6(2), 58-64. https://doi.org/10.47718/jib.v6i2.818

Jannah, A. M. (2016). Faktor-Faktor yang Berhubungan dengan Perlaku Pemberian ASI Eksklusif pada Bayi Usia 6-12 Bulan di Kelurahan Gerem Wilayah Kerja Puskesmas Grogol Kota Cilegon Tahun 2015. Univesitas Islam Negeri Syarif Hidayatullah Jakarta.

Kemenkes. (2018). Peran Pemerntah Dalam Penanganan Kegagalan ASI Eksklusif.

Lestari, D. (2021). Implementasi Kebijakan Pemberian Air Susu Ibu (ASI) Ekslusif Di Dinas Kesehatan Kota Banda Aceh. [Universitas Islam Negeri Ar-Raniry Banda Aceh]. https://repository.ar-raniry.ac.id/id/eprint/16044/

Mariana. (2021). Faktor-Faktor yang Mempengaruhi Pemberian ASI Eksklusif pada Keluarga Tani Kabupaten Pidie Terhadap Anak Stunting Usia 6-24 Bulan. 2021, publikasi online. [Universitas Sumatera Utara]. http://repositori.usu.ac.id/handle/123456/31256

Marifah, T. K. (2019). Faktor yang Mempengaruhi Kegagalan Pemberian ASI Eksklusif pada Bayi Usia 0-6 Bulan di Wilayah Kerja Puskesmas Pegandan Tahun 2019. Universitas Negeri Semarang.

Pitaloka, D., Abrory, R., \& Pramita, A. (2018). Hubungan antara Pengetahuan dan Pendidikan lbu dengan Pemberian ASI Eksklusif di Desa Kedungrejo Kecamatan Waru Kabupaten Sidoarjo. Amerta Nutr. 2018;2(3):265. doi:10.20473/amnt.v2i3.2018.265-270. Amerta Nutrition, 2(3), 265-270.

Purwanto, A., Pramono, R., Asbari, M., Hyun, C. C., Wijayanti, L. M., Putri, R. S., \& Santoso, P. B. (2020). Studi Eksploratif Dampak Pandemi COVID-19 Terhadap Proses Pembelajaran Online di Sekolah Dasar. EduPsyCouns: Journal of Education, Psychology and Counseling, 2(1), 1-12.

Rahmadhan, E., Lubis, G., \& Edison. (2013). Hubungan Pemberian ASI Eksklusif 
dengan Angka Kejadian Diare Akut Pada Bayi Usia 0-1 Tahun di Puskesmas Kuranji Kota Padang. Jurnal Kesehatan Andalas, 2(2).

Salamah, U., \& Prasetya, P. (2019). Faktor-Faktor Yang Mempengaruhi Kegagalan Ibu Dalam Pemberian Asi Eksklusif. Jurnal Kebidanan Malahayati, 5(3), 199 204. https://doi.org/10.33024/jkm.v5i3.1418

Setyaningsih, F. T. E., \& Farapti. (2018). Hubungan Kepercayaan dan Tradisi Keluarga pada Ibu Menyusui dengan Pemberian ASI Eksklusif di Kelurahan Sidotopo, Semampir, Jawa Timur. Jurnal Biometrika Dan Kependudukan, 7(2).

Sholikah, B. (2018). Hubungan Penolong Persalinan, Inisiasi Menyusu Dini dan Dukungan Petugas Kesehatan dengan Perilaku Ibu Dalam Pemberian ASI Eksklusif. Jurnal Keperawatan Muhammadiyah, 3(2), 6-12. https://doi.org/10.30651/jkm.v3i2.1755

Sutrini, E., \& Aulia, H. (2020). Hubungan Faktor-Faktor Pemberian ASI Eksklusif Pada lbu Bekerja Di Rsu Budi Kemuliaan. Jurnal Media Informasi Kesehatan, 7(2), 385-394. https://doi.org/10.36743/medikes.v7i2.243

Syafneli, \& EY, H. (2015). Analisis Faktor-Faktor yang Berhubungan dengan Pemberian ASI Eksklusif di Desa Pasir Jaya Tahun 2014. Journal Martenity and Neonatal, 2(1), 54-61.

Untari, J. (2017). Hubungan Karakteristik Ibu Dan Pemberian ASI Eksklusif. Jurnal FORMISL KesMas Respati, 2(1). http://formilkesmas.respati.ac.id/index.php/formil/article/view/58

Wulandari, A. (2011). Hubungan Tingkat Pengetahuan dengan Perlaku Pemberian ASI Eksklusif Pada Ibu yang Mempunyai Bayi Usia Kurang Dari 6 Bulan di Desa Bangunjiwo Kasihan Bantul. Sekolah Tinggi Ilmu Kesehatan 'Aisyiyah Yogyakarta.

Wulansari, S., \& Pramono, M. S. (2014). Correlation between Family Social Economy Status and Exclusive Breastfeeding in Tanah Kali Kedinding Public Health Centre, Surabaya. Buletin Penelitian Sistem Kesehatan, 17(1), 9-15. 